\title{
Influence of Coupling Agent in Compatibility of Post-consumer HDPE in Thermoplastic Composites Reinforced with Eucalyptus Fiber
}

\author{
André Luis Catto*, Bruno Vicari Stefani, Vanda Ferreira Ribeiro, Ruth Marlene Campomanes Santana \\ Engineering School, Federal University of Rio Grande do Sul - UFRGS, \\ Laboratory of Polymers - LAPOL, Porto Alegre, RS, Brazil
}

Received: June 27, 2013; Revised: February 10, 2014

\begin{abstract}
This study investigates the feasibility of using recycled high density polyethylene (HDPE) and wood fiber from species Eucalyptus grandis $(E U)$ to manufacture experimental composite panels. The use of maleated polyethylene as coupling agent (CA) improved the compatibility between the fiber and plastic matrix. The mechanical properties of the resultant composites were compared with polymer with and without compatibilizer. The influence of the coupling agent (CA) in the polymer matrices and composites were evaluated at different concentrations, checking the physical, mechanical and thermal properties of wood plastic composites (WPC). Results of mechanical, physical and thermal properties showed that concentration of $3 \% \mathrm{w} / \mathrm{w} \mathrm{CA}$ in the polymer matrices was that which showed the best results, but in the composites properties were very similar in all formulations. Based on the findings in this work, it appears that recycled materials can be used to manufacture value-added panels without having any significant adverse influence on material properties.
\end{abstract}

Keywords: wood plastic composite, thermoplastic composite, HDPE, coupling agent, wood flour

\section{Introduction}

Nowadays much emphasis has been given to the preservation and conservation of the environment in order to ensure sustainable development. Among the various damages to the environment, one is related to the lignocellulosic and plastics wastes ${ }^{1}$. The plastics waste generally takes a long time to undergo spontaneous degradation, and when burnt, can produce different degrees of toxicity ${ }^{2}$. Therefore, there is a general tendency to use these polymers and lignocellulosic residues, considering the immense potential value of the processed materials and the implications of waste and pollution resulting from the non-use of such waste . $^{3}$

The development of composites involving the use of lignocellulosic materials as reinforcements in polymeric matrices has grown recycled increasingly in response to environmental conservation, making more frequent in the polymer industry due to the lignocellulosic being renewable, inexpensive, biodegradable and non-toxic. Among the lignocellulosic materials most used for this purpose are sawdust, wood flour, plant fibers and agricultural and agroindustrial lignocellulosic waste ${ }^{4}$. Use of agro-waste materials as a reinforcement in the production of WPCs alleviate the shortage of wood resources, and can have the potential to start a natural fiber industry in countries where there are little or no wood resources ${ }^{5}$. Çöpür et al. ${ }^{6}$ also believe that agricultural byproducts are excellent alternative waste materials to substitute wood because they are plentiful, widespread, and easily available. Apart from their abundance and renewability, utilization of agricultural wastes can be advantageous to economy, environment, and technology.

*e-mail: andrecatto@terra.com.br
However the preparation of such polymer composites with wood requires a good compatibility at the interface from polymeric matrix with the wood $^{7}$. The main concern of obtaining reinforcements by incorporating wood fibers lies in the inherent incompatibility between the hydrophilic fibers and hydrophobic polymers, which results in a poor adhesion ${ }^{6,7}$. Thus, some coupling agents have been used in the modification of fibers, to increase the interfacial adhesion between cellulosic reinforcement and polymeric matrix and thereby improve the mechanical properties of the polymeric composite ${ }^{8}$. The use of coupling agents is an efficient approach to improve the inter-phase compatibility of the composites ${ }^{9-11}$. A coupling agent is a chemical that functions at the interface to create a chemical bridge between the reinforcement and the matrix ${ }^{12}$. The agent improves the interfacial adhesion when one end of the molecule is tied to the reinforcement surface and the functionality at the other end reacts with the polymer phase. Copolymers containing maleic anhydride, such as maleated polypropylene (MAPP) or maleated polyethylene (MAPE), are the most commonly reported coupling agents used in wood plastic composites $^{13,14}$. The anhydride groups of the copolymers can react with the surface hydroxyl groups of wood, forming ester bonds. The other end of the copolymer entangles with the polymer matrix because of their similar polarities ${ }^{15,16}$. Isocyanates have also been used as coupling agents in natural fiber reinforced polymer composites. Urethane links can be formed between the isocyanate functionality and the hydroxyl group of natural fibers ${ }^{17}$, consequently blocking the hygroscopic hydroxyl sites ${ }^{18}$. Silanes are recognized as efficient coupling agents as they can be hydrolyzed to 
expose the active silanol groups toward the hydroxyl groups of the wood, thereby reacting to form chemical bonding ${ }^{19}$.

The aim of this research was to improve the compatibility between HDPE matrix and wood sawdust and to develop WPC materials for structural applications, using postconsumer materials, aiming to reduce the environmental impact and add value to these new materials.

\section{Materials and Methods}

The materials used in this study were the following: post-consumer HDPE, provided from various packaging of cleaning products; eucalyptus flour (EU) of the species Eucalyptus grandis from the southern state of Rio Grande do Sul, Brazil; coupling agent (CA) - grafted polyethylene copolymer with $1 \%$ maleic anhydride (PEgMA) Fusabond E-528, melt flow index of $6.7 \mathrm{~g} / 10 \mathrm{~min}$ and density of $0.922 \mathrm{~g} / \mathrm{cm}^{3}$ from DuPont.

HDPE plastic waste were pre-washing with water, following dried at room temperature for 24 hours. After, they were ground and crushed to size reduction in the form of flakes in a Retsch SM 200 knife mill. The wood flour (EU) passed by size separation in a sieves system with series of 32 and 16 Tyler mesh, and selected particle size of $>250$ and $<500 \mu \mathrm{m}$.

The formulation of the substrates was performed as shown in Table 1:

Mixtures were processed in a single screw extruder (L/D: 22), with the temperature profile of $170^{\circ}-180^{\circ}-190^{\circ} \mathrm{C}$, residence time of $80 \mathrm{~s}$ and rotation of $65 \mathrm{rpm}$. HDPE with the coupling agent (CA) was first processed in the extruder in order to functionalizing the polyolefin, and after added sieved wood flour $(30 \% \mathrm{w} / \mathrm{w})$. After mixing by extrusion, samples were cropped in the shredder. The specimens for mechanical tests were prepared by injection molding (Mini Thermo Scientific Haake MiniJet II) at a temperature of $185^{\circ} \mathrm{C}$ and pressure of $600 \mathrm{bar}$.

\subsection{Characterization}

\subsubsection{Physical testing}

\section{Contact angle and surface energy}

The contact angle measurements were made with RaméHart goniometer (model 100-00), according to ASTM D 724-89. The liquids used for sesil drop test were deionized water and diiodomethane $\left(\mathrm{CH}_{2} \mathrm{I}_{2}\right)$. For all samples were made
10 drops of each liquid, each drop image was measurement of angles using the Surftens 3.0 software. The values obtained in the contact angle tests were used to calculate the surface energy to the samples. The calculation of the surface tension was carried out with the Surftens 3.0 software.

\subsubsection{Thermal testing}

\section{DSC}

The temperatures, fusion and crystallization enthalpies and the degree of crystallinity of HDPE with different compositions from CA were evaluated using a differential exploratory calorimeter (DSC), from TA Instruments (Model Q-20). Samples were subjected to two stages of heating and one cooling, using a rate of $10^{\circ} \mathrm{C} / \mathrm{min}$ in a range $20-200^{\circ} \mathrm{C}$, according to ASTM D 3417. The percentage of crystallinity $(\% \mathrm{Xc})$ was calculated using the reference value of fusion enthalpy of the samples of $100 \%$ crystalline HDPE obtained from the literature ${ }^{10,11}$. Crystallization time was obtained by calculating the cooling cycles observing the samples.

\subsubsection{Mechanical tests}

The tensile tests were performed on a Universal machine, model DL 2000 from EMIC, based on ISO 527-1 standard, using a load cell of $1000 \mathrm{~N}$ and the speed of separation of $2 \mathrm{~mm} / \mathrm{min}$, where were used eight specimens test.

\subsubsection{Morphological tests}

By SEM it is possible to observe the morphology of the polymer surface, orientation and possible changes made. This test was performed for analysis by scanning electron microscopy (SEM), using the JEOL JSM 6060 electron microscope, with a voltage of $10 \mathrm{kV}$ and magnification of 80 times. The samples were manually cut, fixed on stubs with double sided tape and coated with gold. The images of the samples were obtained from the fracture surfaces after tensile test.

\section{Results and Discussion}

\subsection{Physical properties}

\subsubsection{Contact angle and surface energy}

The measurement of the contact angles of pure liquids, with known surface tension and hence surface tensions parameters, on a given solid surface is the common way of

Table 1. Formulation of compatibilized matrices and composites.

\begin{tabular}{lccccc}
\hline & Sample & Matrix & Filler & CA & \% w/w CA \\
\hline Compatibilized Matrices & 1 & HDPE & - & - & - \\
& 2 & HDPE & - & PEgMA & 1 \\
& 3 & HDPE & - & PEgMA & 3 \\
& 4 & HDPE & - & PEgMA & 5 \\
Compatibilized Composites & 5 & HDPE & - & PEgMA & 7 \\
& 7 & HDPE & EU & PEgMA & 1 \\
& 8 & HDPE & EU & PEgMA & 3 \\
& 9 & HDPE & EU & PEgMA & 5 \\
\hline
\end{tabular}


obtaining the surface energy of the solid material ${ }^{20}$. Figure 1 shows results of contact angles from HDPE, compatibilized HDPE matrices (HDPE/CA) and the compatibilized composites (HDPE/EU/CA).

The highest contact angles were obtained with water, whereas diiodomethane gave the lowest contact angles. The insertion of polar groups at the surface nonpolar polymer causes the contact angle decreases ${ }^{20}$. Thus, there is a change of its hydrophobicity characteristics ${ }^{20}$.

Results of the contact angle with water show that HDPE, being nonpolar polymer, exhibits high hydrophobicity, with values of contact angle above $80^{\circ}$. When incorporated the coupling agent (CA), contact angle values in composites decreases as there is an increased concentrations of CA, however showing a range of values very similar, between 60 and $70^{\circ}$, indicating a higher wettability and consequently improved adhesion. The decrease of the contact angle in this case indicated that the HDPE surface has become less hydrophobic, i.e., more wettable with the process and may thus lead to an increased interaction of the fibers for obtaining a good performance in the composites ${ }^{11,21}$. For compatibilized matrices, there was also a slight improvement in wettability, although the contact angle values were almost equal. As an example the behavior of the liquid drop on the surface and its respective angles are shown in Figures 2a,b, presenting drops images on the HDPE and HDPE/CA 3\% surface respectively.

Relationships between adhesion strength and surface properties then provide a framework upon which adhesion

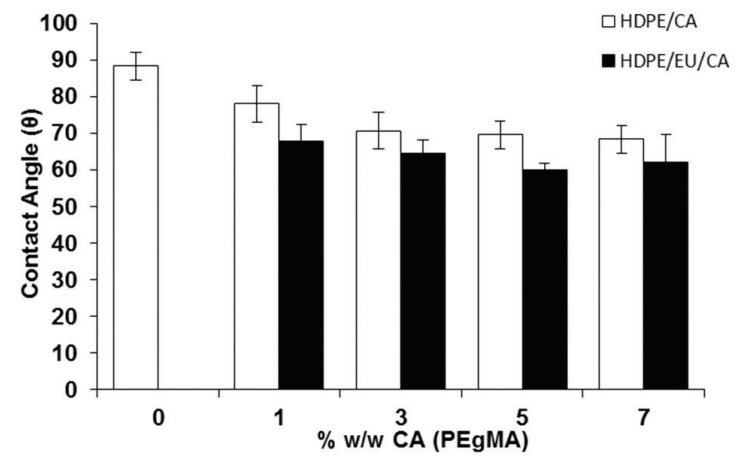

Figure 1. Contact angle of water on the samples surface. mechanisms are discussed. This knowledge is significant to understand the adhesion of complex heterogeneous multicomponent composites and also has direct applications for the wood plastic composites (WPC) industry. It was proposed by $\mathrm{Wu}^{21}$ and it is accepted widely that the intermolecular energy between two materials results from the summation of a dispersion component and a polar component. Since the surface free energy (or surface tension) is proportional to the intermolecular energy, the surface free energy itself can be considered as a sum of a dispersion component and a polar component ${ }^{21}$. According to $\mathrm{Wu}^{21}$ this method, known as harmonic mean may be successfully applied in the case of interaction between a polymer and a liquid either, as is the case studied in this work. Using two liquids with $\gamma \mathrm{LV}^{\mathrm{d}}$ and $\gamma \mathrm{LV}^{\mathrm{p}}$ known, can be determined $\gamma \mathrm{S}^{\mathrm{d}}$ and $\gamma \mathrm{S}^{\mathrm{p}}$ by means of contact angle measurements and using Equation 1. In general, Equation 1 is written in the algorithms of electronic measurement of contact angle and surface energy equipment.

$$
\gamma L V(\cos \theta+1)=\frac{4\left(\gamma S^{\mathrm{d}} \gamma L V^{\mathrm{d}}\right)}{\gamma \mathrm{S}^{\mathrm{d}}+\gamma L V^{\mathrm{d}}}+\frac{4\left(\gamma \mathrm{S}^{\mathrm{p}} \gamma L V^{\mathrm{p}}\right)}{\gamma \mathrm{S}^{\mathrm{p}}+\gamma L V^{\mathrm{p}}}
$$

where: $\gamma L V=$ surface tension of the liquid, $\gamma S^{d}=$ dispersive component of solid surface, $\gamma \mathrm{LV}^{\mathrm{d}}=$ dispersive component of the surface liquid, $\gamma \mathrm{S}^{\mathrm{p}}=$ non-dispersive component (or polar) on the solid surface, $\gamma \mathrm{LV}^{\mathrm{p}}=$ non-dispersive component (or polar) of the surface liquid.

With results of contact angle from samples with water and diiodomethane are reached results of surface tension of the samples, as shown in Figure 3.

In this regard, for experimental results, incorporation of the coupling agent (CA) was efficient, leading to an increase in surface energy of the polymeric matrix and composites, which thus promoted better interaction of the polymeric matrix with wood waste (EU). Redighieri ${ }^{7}$ studied use of wood waste in the production of composites with recycled polyethylene, where polyethylene was functionalized with maleic anhydride (PE-g-MA) as coupling agent to provide better adhesion between the matrix and the dispersed phase. The results showed that treatment of the wood waste flour with PE-g-MA increased mechanical properties of the composite compared to composites containing untreated waste. The HDPE/EU/CA composites were those that

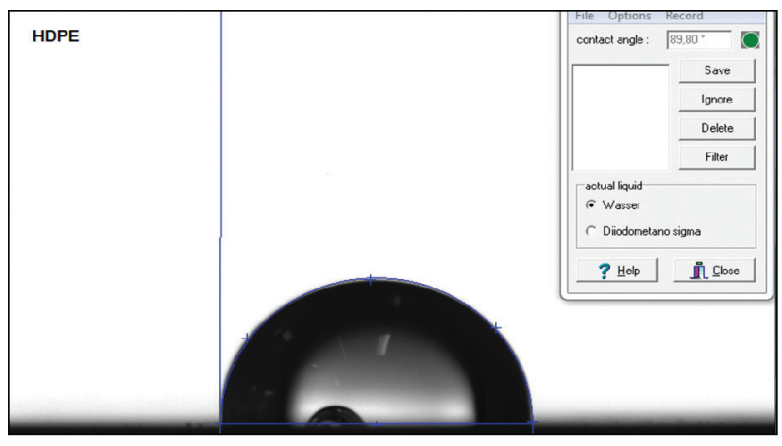

(a)

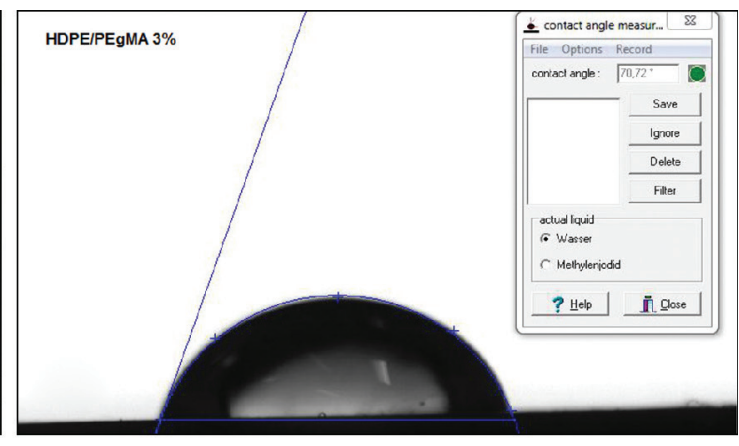

(b)

Figure 2. Image of the water drop profile on the surface of: (a) HDPE and (b) HDPE/CA 3\%. 
showed the best result, thus indicating a better adhesion between the phases.

\subsection{Thermal properties}

\subsubsection{DSC}

The DSC analyzes were performed only in the compatibilized matrix with $\mathrm{CA}$ in order to verify thermal properties with different concentrations of coupling agent and thus set the optimal concentration to be used for the manufacture of wood plastic composites (WPC). Table 2 indicates the results of DSC analysis, which shows the values of temperature, fusion and crystallization enthalpy, crystallization time and crystallinity of HDPE samples without and with coupling agent (HDPE/CA).

The CA variation caused no significant changes in the thermal properties of compatibilized HDPE (Tf, Tc). However, according to Lu et al. ${ }^{22}$, and Liang et al. ${ }^{23}$, there is an optimum concentration of these agents to promote better adhesion between the matrix and the dispersed phase and consequently, that the composites show improvement in their properties.

Regarding the change of enthalpy $(\Delta \mathrm{H})$, there are differences between all samples, and there was a decrease in both the enthalpy of fusion $(\Delta \mathrm{Hf})$ as the crystallization enthalpy $(\Delta \mathrm{Hc})$ relative to the compatibilized HDPE samples. However it is observed that HDPE sample with $3 \% \mathrm{w} / \mathrm{w}$ of CA showed opposite behavior to the other, with higher values of $\Delta \mathrm{Hf}$ the first and second heating, so as $\Delta \mathrm{Hc}$. This sample was analyzed again to confirm the result, which confirmed this behavior. The HDPE/CA 3\% w/w

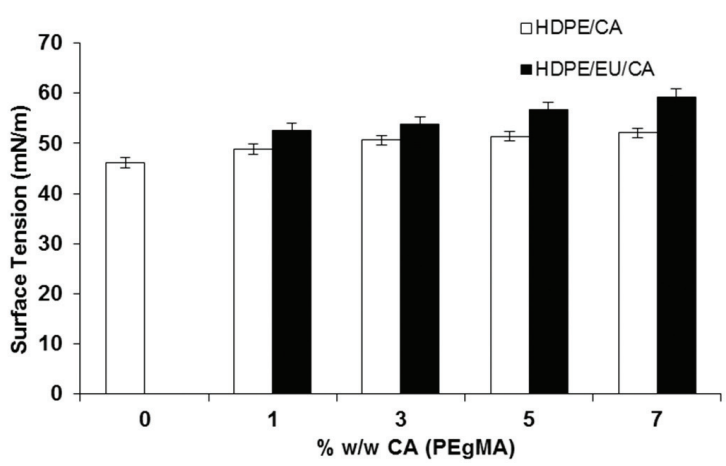

Figure 3. Surface tension of HDPE matrices and its composites. when subjected to the second heating cycle reorganized its structure and showed a variation of enthalpy $(\Delta \mathrm{H})$ higher than that in the first heating. Compatibilized HDPE also had lower crystallinity index than the pure HDPE, with the exception also of the HDPE/CA sample (3\% w/w).

In general, coupling agent in the HDPE/CA $3 \%$ showed a tendency to act as a nucleating agent, ie, make the polymer can achieve at times smaller, a larger proportion of crystalline material ${ }^{24-26}$. At the beginning of crystallization of the composites there is formation of larger crystals, which accelerates the crystallization ${ }^{27,11}$. At the end of the process, these crystals hinder the arrangement of smaller chains, causing an increase in the crystallization total time (tc). From the data obtained, HDPE/CA 3\% showed higher $\mathrm{Xc}$ and lower tc than the other samples, being chosen so this concentration of coupling agent (CA). The result of the higher degree of crystallinity indicates the best performance of this formulation. For this reason and also for economic reasons, taking into account the "cost x properties" shown in the tests, the concentration of $3 \% \mathrm{w} / \mathrm{w}$ of CA was determined as the most appropriate concentration.

\subsection{Mechanical properties}

Table 3 shows results of tensile strength of postconsumer HDPE matrices with the coupling agent (HDPE/ CA) and compatibilized composites (HDPE/EU/CA).

Among the compatibilized composites, those who presented the best results were those with levels of 3 and $7 \% \mathrm{CA}$, respectively, with tensile strength values similars, being the composite with 3\% CA had the highest value. However, the differences between all coupled composites were not so significant.

In general, composites where was added the coupling agent (CA) showed clearly increased stiffness and mechanical strength in comparison with the compatibilized HDPE matrices.

HDPE is a highly tenacious matrix, ie, is able to undergo a high degree of deformation before breaking, but has low tensile strength and low modulus of elasticity. It is observed for the results of composites that wood fiber was able to promote the effect of reinforcement in matrix thermoplastic, increasing tensile strength and elasticity modulus (Table 3 ).

Increases in tensile strength observed in compatibilized composites indicate improved transfer tensile from matrix for cellulosic reinforcement in interface resulting in a probable occurrence of mechanical anchoring or chemical

Table 2. Thermal behavior of HDPE without and with different concentrations from CA.

\begin{tabular}{|c|c|c|c|c|c|c|c|c|c|}
\hline \multicolumn{10}{|c|}{ DSC } \\
\hline \multirow[t]{2}{*}{ Sample } & \multicolumn{3}{|c|}{$1^{\circ}$ Heating } & \multicolumn{3}{|c|}{ Cooling } & \multicolumn{3}{|c|}{$2^{\circ}$ Heating } \\
\hline & $\operatorname{Tf}\left({ }^{\circ} \mathbf{C}\right)$ & $\Delta \mathbf{H f}(\mathbf{J} / \mathbf{g})$ & $\mathrm{Xc}(\%)$ & Tc $\left({ }^{\circ} \mathbf{C}\right)$ & $\Delta \mathbf{H c}(\mathbf{J} / \mathbf{g})$ & tc (min) & $\operatorname{Tf}\left({ }^{\circ} \mathbf{C}\right)$ & $\Delta \mathbf{H f}(\mathbf{J} / \mathbf{g})$ & $\mathrm{Xc}(\%)$ \\
\hline HDPE & 130.3 & 164 & 56 & 118.8 & 194 & 5.8 & 132.8 & 197 & 68 \\
\hline HDPE/CA $1 \%$ & 131.0 & 160 & 55 & 118.0 & 176 & 6.0 & 133.0 & 177 & 61 \\
\hline HDPE/CA $3 \%$ & 131.5 & 194 & 67 & 118.9 & 201 & 5.5 & 132.8 & 208 & 72 \\
\hline HDPE/CA $5 \%$ & 131.3 & 129 & 44 & 117.8 & 150 & 6.0 & 132.9 & 148 & 51 \\
\hline HDPE/CA $7 \%$ & 130.0 & 135 & 46 & 118.9 & 144 & 5.5 & 131.5 & 152 & 52 \\
\hline
\end{tabular}

$\Delta \mathbf{H f}$ - enthalpy of fusion, Tf - melting temperature; Xc - crystallinity index; $\Delta \mathbf{H c}$ - enthalpy of crystallization, Tc - crystallization temperature; tc - crystallization time. 
interactions between the anhydride groups and the hydroxyls of cellulose in polymer-wood interface ${ }^{28-30}$.

Regarding the modulus of elasticity, HDPE without treatment with $\mathrm{CA}$ showed a higher modulus than

Table 3. Tensile strength at break of HDPE, compatibilized HDPE matrices and composites.

\begin{tabular}{lcc}
\hline \multicolumn{1}{c}{ Samples } & \multicolumn{2}{c}{ Mechanical Properties } \\
\cline { 2 - 3 } & \multicolumn{2}{c}{ Tensile Test } \\
\cline { 2 - 3 } & $\begin{array}{c}\text { Tensile Strength at } \\
\text { rupture (MPa) }\end{array}$ & $\begin{array}{c}\text { Modulus of Young } \\
\text { (MPa) }\end{array}$ \\
\hline HDPE & $33 \pm 1,5$ & $520 \pm 57$ \\
HDPE/CA 1\% & $28 \pm 2,5$ & $372 \pm 77$ \\
HDPE/CA 3\% & $31 \pm 3,2$ & $360 \pm 70$ \\
HDPE/CA 5\% & $29 \pm 1,7$ & $475 \pm 78$ \\
HDPE/CA 7\% & $29 \pm 1,3$ & $337 \pm 55$ \\
HDPE/EU/CA 1\% & $35 \pm 1,8$ & $596 \pm 55$ \\
HDPE/EU/CA 3\% & $40 \pm 2,4$ & $651 \pm 45$ \\
HDPE/EU/CA 5\% & $36 \pm 1,2$ & $695 \pm 54$ \\
HDPE/EU/CA 7\% & $39 \pm 1,8$ & $650 \pm 71$ \\
\hline
\end{tabular}

those compatibilized, but smaller modulus compared to composites of HDPE/EU/CA. Among the compatibilized composites, all showed similar results. Across the statistical analysis, it was found that there was no significant difference between all the composites. Thus, for results of the mechanical properties of tensile strength and the modulus of elasticity, in general the HDPE-EU composites with coupling agent (CA) had higher result compared to HDPE and compatibilized HDPE matrices.

\subsection{Morphological Properties}

By scanning electron microscopy was possible to evaluate the efficiency of the dispersion of the cellulosic filler in the thermoplastic matrix and the capacity of wetting the surface fiber for thermoplastic matrix as a way to evaluate the efficiency of coupling agent ${ }^{31,32}$. Aspects related with wettability and level of fiber-matrix interfacial adhesion can be observed in the micrographs presented.

Figure $4 \mathrm{a}$ shows the micrograph of the fracture surface after the tensile test of HDPE/EU/CA $1 \%$ composite, where there is the presence of various structures like fibrils, characteristics for polymeric matrix, and some holes promoted by removal of the filler, which indicates that there

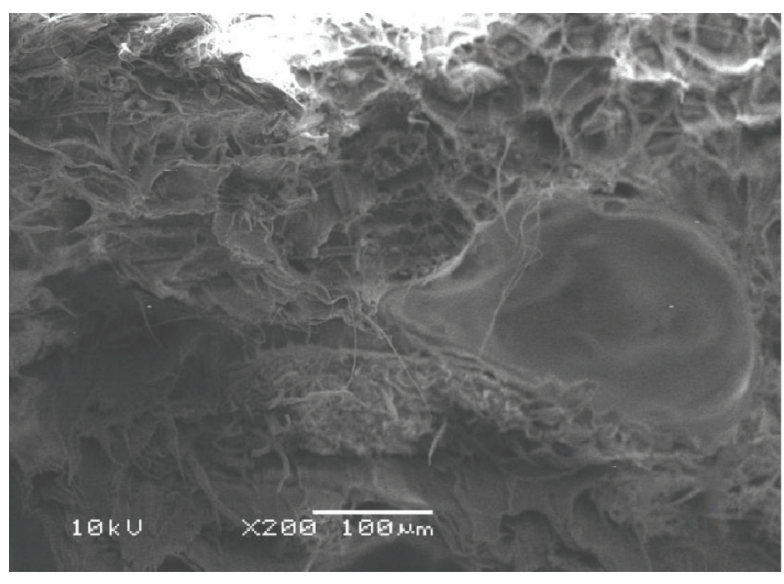

(a)

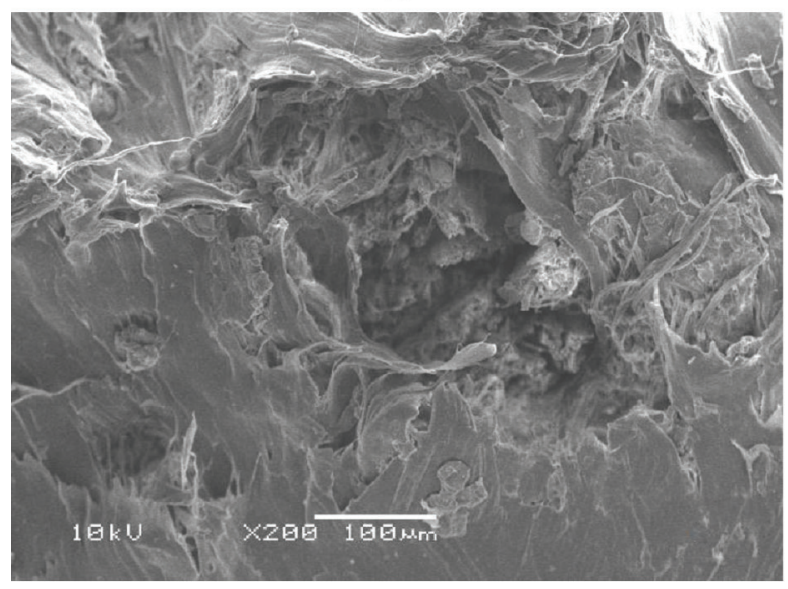

(c)

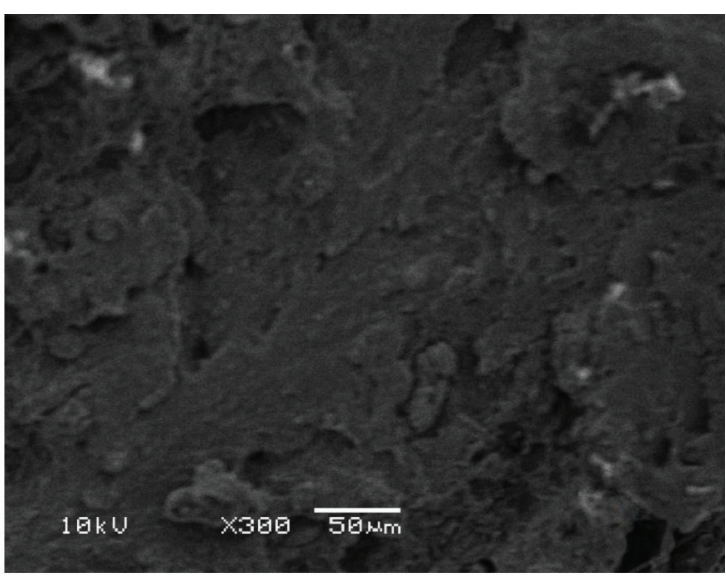

(b)

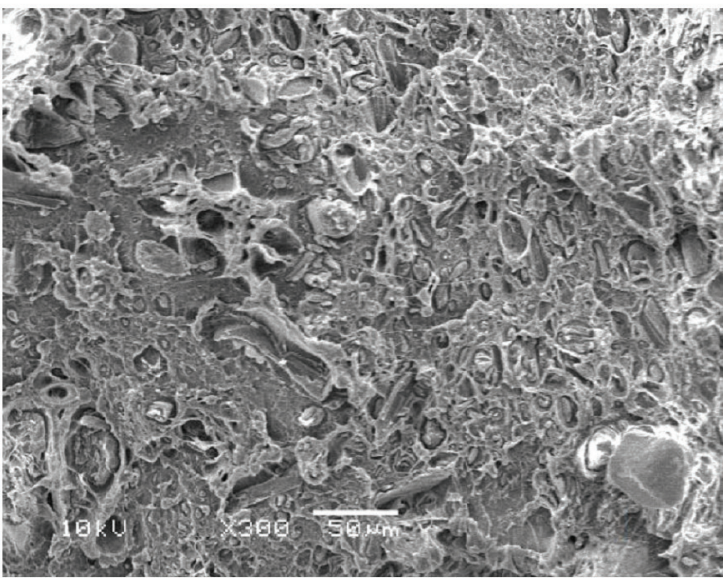

(d)

Figure 4. SEM micrographs of fracture surfaces of HDPE/EU/CA 1\% (a), HDPE/EU/CA 3\% (b), HDPE/EU/CA 5\% (c) and HDPE/EU/ CA 7\% (d) composites. 
is a poor interaction between fiber and polymeric matrix ${ }^{33}$. In the Figure $4 \mathrm{~b}$ is a micrograph of the fracture surface from HDPE/EU/CA 3\% composite where can be seen that there are several particles of fiber presents, some that are not fully adhered to the polymeric matrix, and smaller ones are fully adhered, demonstrating a good compatibility between the two phases ${ }^{34,35}$. Also presents some gaps in its structure, however the composite is more homogeneous, where the filler particles are better attached to the HDPE matrix, indicating that the CA has acted positively on the interfacial adhesion of the polymeric matrix with reinforcement ${ }^{36,37}$, which can be also indicated by the results of tensile strength the composites.

The SEM micrographs of fracture surface from HDPE/ EU/CA 5\% (c) and HDPE/EU/CA 7\% (d) composites also showed structures like fibrils, characteristics for polymeric matrix, and also some holes, but showing a good compatibility between matrix and reinforcement, however it was find a lower interaction between polymer matrix and the fiber in relation to HDPE/EU/CA $3 \%$.

Images shown clearly that the coupling agent (CA) provides an improved interfacial adhesion between the cellulosic fiber and thermoplastic matrix independent of wood size. The images confirm the results obtained in mechanical tests where the compatibilized samples showed an increase of strength in relation to the non-compatibilized compositions.

\section{References}

1. Spinacé MAS and De Paoli MA. A Tecnologia de Reciclagem de Polímeros. Química Nova. 2005; 28:65-72. http://dx.doi. org/10.1590/S0100-40422005000100014

2. Forlin FS and Faria AF. Recycling of plastic packaging. Polymers. 2002; 12:1-10.

3. Nothenberg M. Growing interest in the use of natural fibers. Brazilian Yearbook of Plastic; 1996. p. 6-15.

4. Bohn AR and Szücs CA. Comportamento mecânico da linha de cola nos elementos de madeira laminada colada. In: Annals of Brazilian Meeting on Wood and Wood Structures. Belo Horizonte; 1995. p. 579.

5. Panthapulakkal S and Sain M. Agro-residue reinforced high-densitypolyethylene composites: fiber characterization and analysis of composite properties. Composites Part A 38. 2007; 38(6):1445-1454. http://dx.doi.org/10.1016/j. compositesa.2007.01.015

6. Çöpür Y, Güler C, Akgül M and Tasçıoglu C. Some chemical properties of hazelnut husk and its suitability for particleboard production. Building and Environment. 2007; 42(7):25682572. http://dx.doi.org/10.1016/j.buildenv.2006.07.011

7. Redighieri KI. Study of composite wood particles and recycled LDPE in the presence of compatibilizing agents [Thesis]. Rio de Janeiro: Federal Rural University of Rio de Janeiro; 2006.

8. Hillig E. Technical Feasibility of Production of Composite Polyethylene (HDPE) reinforced with wood waste and byproducts of the furniture industry [Thesis]. Curitiba: Federal University of Parana; 2006.

\section{Conclusions}

After analyzing the physical, mechanical, thermal and morphological properties, concentration of $3 \% \mathrm{w} / \mathrm{w}$ CA was more suitable for the production of materials, especially by DSC results that showed the most interesting characteristics make this concentration to be applied to the composites.

All composites treated with coupling agents showed a better thermal stability when compared to compatibilized HDPE matrices. The results observed by the contact angle with the surface and morphological properties show an improvement in interfacial adhesion between the components of the composites (HDPE/EU/CA) when it is used the maleic anhydride as coupling agent, corroborating with the performance obtained in mechanics tests. The result of the physical and mechanical properties in general indicates that the use of recycled polyolefins is a viable alternative for the production of new materials and can therefore be used in many new applications, even in construction, thus contributing to reduction in impacts to the environment and enabling new sustainable alternatives.

\section{Acknowledgements}

The authors would like to thank CAPES for the financial support, LABIOMAT laboratory and Chemistry Institute by allowing the injection of the tensile specimens, LACER laboratory for contact angle test and Vanda F. Ribeiro of Softer Brazil Company for conducting the mechanical traction test.

9. Nourbakhsh A and Ashori A. Wood plastic composites from agro-waste materials: Analysis of mechanical properties. Bioresource Technology. 2010; 7(101):25252528. PMid:20004095. http://dx.doi.org/10.1016/j. biortech.2009.11.040

10. Nourbakhsh A, Karegarfard A, Ashori A and Nourbakhsh A. Effects of particle size and coupling agent on mechanical properties of particle-reinforced composites. Journal Thermoplastic Composite Materials; 2009. http://dx.doi. org/ 10.1177/0892705709340962

11. Kazayawoko M, Balatinecz JJ and Matuana LM. Surface modification and adhesion mechanisms in woodfiberpolypropylene composites. Journal of Materials Science. 1999; 34(24):6189-6199. http://dx.doi. org/10.1023/A:1004790409158

12. Ou R, Zhao H, Sui S, Song Y and Wang Q. Reinforcing effects of Kevlar fiber on the mechanical properties of wood-flour/ high-density-polyethylene composites. Composites Part A: Applied Science and Manufacturing. 2010; 41(9):1272-8. http://dx.doi.org/10.1016/j.compositesa.2010.05.011

13. Sanadi AR, Caulfield DF, Jacobson RE, and Rowell RM. Renewable agricultural fibers as reinforcing fillers in plastic: Mechanical Properties of Kenaf Fiber-Polypropylene Composites. Industrial \& Engineering Chemistry Research. 1995; 34(5):1889-1896. http://dx.doi.org/10.1021/ ie $00044 \mathrm{a} 041$

14. Nourbakhsh A and Ashori A. Preparation and properties of wood plastic composites made of recycled HDPE. Composite Materials. 2009; 43(8):877-883. http://dx.doi. org/10.1177/0021998309103089 
15. Ashori A and Nourbakhsh A. Effects of nanoclay as a reinforcement filler on thephysical and mechanical properties of wood based composite. Journal of Composite Materials. 2009; 43:(18) 1869-1875. http://dx.doi. org/10.1177/0021998309340936

16. Ashori A. Wood-plastic composites as promising greencomposites for automotive industries. Bioresource Technology. 2008; 99(11):4661-4667. PMid:18068352. http:// dx.doi.org/10.1016/j.biortech.2007.09.043

17. Maldas D and Kokta B. Improving adhesion of wood fiber with polystyrene by the chemical treatment of fiber with a coupling agent and the influence on the mechanical properties of composites. Journal of Adhesion Science and Technology. 1989; 3(1):529-539. http://dx.doi. org/10.1163/156856189X00380

18. Reichelt L and Poller S. Über die Umsetzung von Cellulose und Lignin mit Isocyanaten bzw. Isocyanatgruppenhaltigen Präpolymeren. Acta Polymerica. 1981; 32(3):172-176. http:// dx.doi.org/10.1002/actp.1981.010320309

19. Xie Y, Hill CAS, Xiao Z, Militz H and Mai C. Silane coupling agents used for natural fiber/polymer composites: A review. Composites Part A: Applied Science and Manufacturing. 2010; 41(7):806-19. http://dx.doi. org/10.1016/j.compositesa.2010.03.005

20. Gindl M, Sinn G, Gindl W, Reiterer A and Tschegg S. A comparison of different methods to calculate the surface free energy of wood using contact angle measurements. Colloids and Surfaces A: Physicochemical and Engineering Aspects. 2001; 181(1-2):279-287. http://dx.doi.org/10.1016/ S0927-7757(00)00795-0

21. Wu S. Calculation of interfacial tension in polymer systems. Journal Polymer Science Part C: Polymer Symposia. 1971; 34(1):19-30. http://dx.doi.org/10.1002/ polc.5070340105

22. Lu JZ, Wu Q and Negulescu II. Wood-fibre/high-densitypolyethylene composites: coupling agent performance. Journal of Applied Polymer Science. 2005; 96(1):93-102. http://dx.doi. org/10.1002/app.21410

23. Liang G, Xu J, Bao S and Xu W. Polyethylene/maleic anhydride grafted polyethylene/organic-montmorillonite nanocomposites. I. Preparation, microstructure, and mechanical properties. Journal of Applied Polymer Science. 2004; 91(6):3974-3980. http://dx.doi.org/10.1002/app.13612

24. Stark NM, Matuana LM and Clemons CM. Effect of processing method on surface and weathering characteristics of wood-flour/HDPE composites. Journal of Applied Polymer Science. 2004; 93(3):1021-1030. http://dx.doi.org/10.1002/ app. 20529

25. Ichazo MN, Albano C, González J, Perera R, Candal MV. Polypropylene/wood flour composites: treatments and properties. Composite Structures. 2001; 54(2-3):207-214. http://dx.doi.org/10.1016/S0263-8223(01)00089-7
26. Catto AL and Santana RMC. Evaluation of Coupling Agent in Load/Matrix Interaction: Mechanical and Morphological Properties. In: IX Argentine Symposium of Polymers - SAP 2011; 2011; Bahía Blanca. 2011. p. 53-58.

27. Marcovitch NE, Aranguren MI and Reboredo MM. In: Proceedings of the Natural Polymers and Composites IV; 2002; São Pedro; 2002. p. 416-421.

28. Kuruvilla J, Medeiros E and Carvalho L. Polyester matrix composites reinforced by short sisal fibers. Polymers. 1999; 11:136-141.

29. Keener TJ, Stuart RK and Brown TK. Maleated coupling agents for natural fibre composites. Composites Part A: Applied Science and Manufacturing. 2004; 35(3):357-362. http:// dx.doi.org/10.1016/j.compositesa.2003.09.014

30. Candian LM and Dias AA. Study of High Density Polyethylene Recycled for Use in Structural Elements. Journal of Structural Engineering. 2009; 51:1-16.

31. Gupta AK, Ratnam BK and Srinivasan KR. Impact toughening of polypropylene by ethylene vinyl acetate copolymer. Journal of Applied Polymer Science. 1992; 45(7):1303-1312. http:// dx.doi.org/10.1002/app.1992.070450718

32. Martins CG, Larocca NM, Paul DR and Pessan LA. Nanocomposites formed from polypropylene/EVA blends. Polymer. 2009; 50(7):1743-1754. http://dx.doi.org/10.1016/j. polymer.2009.01.059

33. Koenig KM and Sypkens CW. Wood-Plastic Composites For Market Shore. Wood and Wood Products. 2002; 107(5):49-58.

34. Mohanty S and Nayak SK. Dynamic and steady state viscoelastic behavior and morphology of MAPP treated $\mathrm{PP} /$ sisal composites. Materials Science and Engineering: A. 2007; 443(1-2):202-208. http://dx.doi.org/10.1016/j. msea.2006.08.053

35. Spinacé MAS, Fermoselli KKG and De Paoli M-A. Recycled polypropylene reinforced with curaua fibers by extrusion. Journal of Applied Polymer Science. 2009; 112(6):3686-3694. http://dx.doi.org/10.1002/app.29683

36. Migneault S, Koubaa A, Erchiqui F, Chaala A, Englund $\mathrm{K}$ and Wolcott MP. Effects of processing method and fiber size on the structure and properties of wood-plastic composites. Composites Part A: Applied Science and Manufacturing. 2009; 40(1):80-85. http://dx.doi.org/10.1016/j. compositesa.2008.10.004

37. Adhikary KB and Pang S. Dimensional stability and mechanical behaviour of wood-plastic composites based on recycled and virgin high-density polyethylene (HDPE). Composites Part B: Engineering. 2008; 39(5):807-815. http://dx.doi.org/10.1016/j. compositesb.2007.10.005 